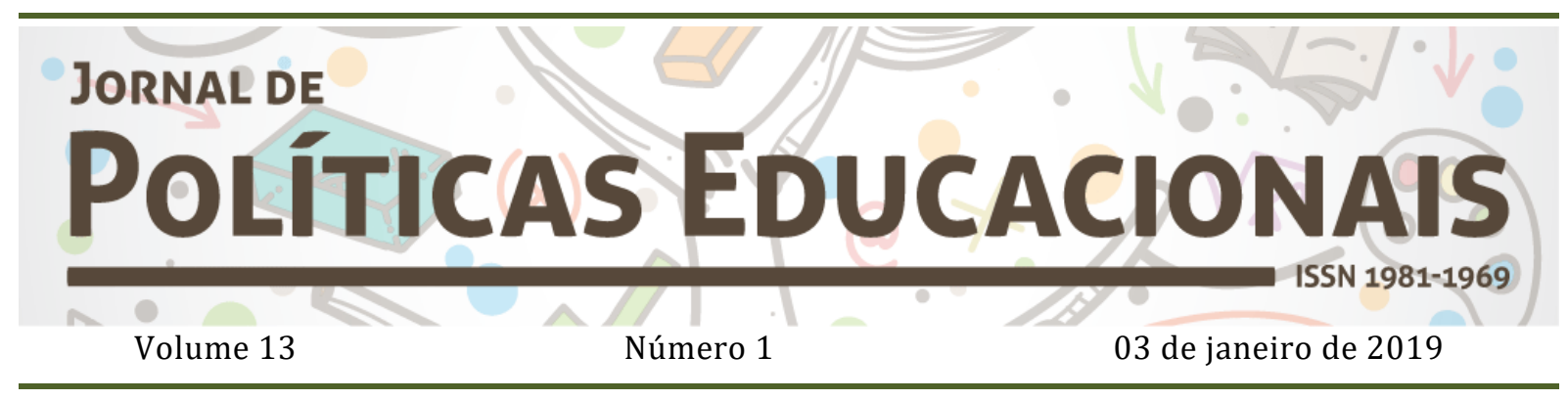

\title{
Política educacional e a avaliação em larga escala como elemento de regulação da educação
}

\author{
Educational policy and large scale evaluation as an element of \\ education regulation
}

\section{Política educativa y evaluación a gran escala como elemento de regulación de la educación}

\author{
Rosangela Cely Branco Lindoso ${ }^{1}$
}

Ana Lúcia Felix dos Santos²

Citação: LINDOSO, R. C. B.; SANTOS, A. L. F. Política educacional e a avaliação em larga escala como elemento de regulação da educação. Jornal de Políticas Educacionais. V. 13, n. 1. Janeiro de 2019.

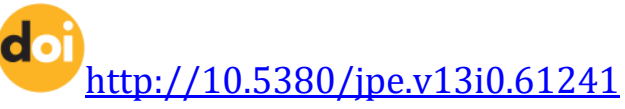

\begin{abstract}
Resumo:
Este texto busca discutir a política educacional e as formas de regulação da educação, via processos de avaliação em larga escala, tomando como referente o processo de mediação que demarca o contexto sóciopolítico. A discussão é desenvolvida da seguinte forma: primeiro debate-se o conceito de regulação, em seguida, explicita-se como se processa a regulação e a intervenção nas políticas de educação em diferentes contextos. Na sequência, discute-se esse processo a partir da introdução da avaliação em larga escala como elemento de regulação da educação no Brasil. Os achados revelam que a avaliação em larga escala tem sido utilizada enquanto dispositivo de regulação educacional, cuja preocupação está focada no controle dos resultados e não nos processos.

Palavras Chave: Política Educacional; Regulação; Avaliação em larga escala.
\end{abstract}

Abstract:

This text seeks to discuss educational policy and regulating education ways, through large-scale evaluation processes, taking as reference the mediation process that demarcates the socio-political context. The discussion is developed as follows: first, the concept of regulation is discussed; then becomes clear how regulation and intervention in education policies in different contexts is carried out; this

\footnotetext{
${ }^{1}$ Doutora em Educação (UFPE). Professora do Departamento de Educação Física da Universidade Federal Rural de Pernambuco. E-mail: roxente@ hotmail.com

${ }^{2}$ Doutora em Educação (UFPE). Professora e Pesquisadora do Programa do Programa de Pós-Graduação em Educação da Universidade Federal de Pernambuco. E-mail: analufelix@ gmail.com
} 
process is discussed after the introduction of large-scale evaluation as an element of education regulation in Brazil. The findings reveal that large-scale evaluation has been used as an educational regulatory device, whose concern is focused on the control of results and not on processes.

Keywords: Educational Policy; Regulation; Large-scale evaluation

\section{Resumen}

Este texto busca discutir la política educativa y las formas de regulación de la educación, a través de procesos de evaluación a gran escala, tomando como referente el proceso de mediación que demarca el contexto socio-político. La discusión se desarrolla de la siguiente manera: primero se debate el concepto de regulación, a continuación, se explicita cómo se procesa la regulación y la intervención en las políticas de educación en diferentes contextos. En consecuencia, se discute este proceso a partir de la introducción de la evaluación a gran escala como elemento de regulación de la educación en Brasil. Los hallazgos revelan que la evaluación a gran escala ha sido utilizada como dispositivo de regulación educativa, cuya preocupación está enfocada en el control de los resultados y no en los procesos.

Palabras clave: Política Educativa; la regulación; Evaluación a gran escala.

\section{Introdução}

Inserido no debate sobre políticas públicas para educação, este texto problematiza a relação entre as formas de regulação da educação e do trabalho docente via processos de avaliação em larga escala, tomando como referente o processo de mediação que demarca o contexto sócio-político. Assim, procuraremos evidenciar como as políticas de educação vão sendo direcionadas por meio das avaliações em larga escala para formar uma sociabilidade compatível com o mercado, o que vem interferindo tanto na formação dos estudantes quanto no trabalho docente.

A instauração da lógica neoliberal de governar favoreceu o avanço de ações de regulação nas políticas educacionais expressas, dentre outras formas, na adoção de avaliações em larga escala. Estados e municípios brasileiros são instados a assumir essas estratégias como parte de seu direcionamento na gestão da educação, o que acaba por se configurar em estratégias de controle e regulação da educação pública.

Parte-se da idéia de que para se compreender a política educacional em sua forma mais global, é preciso entender alguns dos nexos que se estabelecem entre a política, a economia e a sociedade. Assim, a discussão aportará sobre a noção de regulação e sua aplicação em diferentes contextos. Entendemos, também, que a avaliação em larga escala, enquando uma estratégia de regulação da educação, vem se legitimando nas políticas de educação no Brasil.

A partir desse entendimento, este texto é organizado da seguinte forma: primeiro debate-se o conceito de regulação, em seguida explicita-se como se processa a regulação e a intervenção nas políticas de educação em diferentes contextos. Na sequência, discute-se o processo a partir da introdução da avaliação em larga escala 
LINDOSO, R. C. B.; SANTOS, A. L. F. Política educacional e a avaliação em larga escala como elemento de regulação da educação

como elemento de regulação da educação no Brasil. A regulação por meio das avaliações está focada no controle dos resultados e não nos processos no sentido de formar uma sociabilidade.

\section{Regulação: um conceito em destaque na atualidade}

É possível dizer que o conceito de regulação ${ }^{3}$ emerge do campo econômico, na busca de explicar as crises capitalistas. Um dos pioneiros nos estudos sobre a teoria da regulação foi G. Destanne Bernis, que utilizou a expressão nas ciências sociais, utilizando elementos da teoria sistêmica para atualizar a análise marxista sobre as questões do capitalismo. Construída no final da década de 70, numa sequência longa de estudos sobre os Estados Unidos, França, Japão, Coreia, Taiwan e de estudos comparativos, na América Latina, com Chile, México, Venezuela, Argentina e Brasil (BOYER,1990).

Esse autor buscou ainda estudar a transformação das relações sociais, simultaneamente econômicas e não econômicas, que se organizam em estruturas e que dão sequencia ao modo de reprodução capitalista. A teoria da regulação ajuda a entender processos políticos e econômicos na análise da intervenção do Estado. A questão de fundo da teoria é identificar como as economias se expandem e se reproduzem, considerando as crises de acumulação e as relações sociais antagônicas, captando as diferenças e dinâmicas de cada fase do capitalismo de forma geral e específica, em cada sociedade. Salientando que a relação causa e efeito não se produz da mesma maneira em sociedades distintas, ou seja, de acordo com as peculiaridades, a regulação pode ser viabilizada ou não (BOYER, 1990).

Isto significa dizer que o foco investigativo recai, ao mesmo tempo, no modo como se processa a acumulação do capital e no modo como são tratadas as crises cíclicas, partindo-se da premissa marxista de que estas são inerentes às economias capitalistas. Neste contexto, a focalização simultânea dos dois modos é feita por meio do estudo da regulação dessas economias e da realidade social na qual elas se inserem consideradas nas suas especificidades históricas (AZEVEDO \& GOMES, 2009, p. 100).

Boyer (1990) nos alerta que esse termo, ao mesmo tempo sedutor e generalizante, acabou por ser tratado com diferentes sentidos, que podem até mesmo ser opostos, tais como: a regulação como conceito transversal à teoria dos sistemas; a

\footnotetext{
${ }^{3} \mathrm{O}$ Ato de regular é ação legítima do Estado por sua própria natureza histórica, politicamente há uma redefinição desta ação, com a finalidade de atender às mudanças na estrutura e na forma de governar, gerando novas formas de regulação que decorrem desse processo. (FREITAS, 2005).
} 
regulação como intervenção ativa e consciente do Estado ou de outras organizações coletivas; a regulação como conjunção dos mecanismos que promovem a reprodução geral, tendo em vista as estruturas econômicas e as formas sociais vigentes. Ele nos diz que essa polissemia promoveu uma multiplicação de referências e certa confusão, e adota a última concepção como a que ele explora, pois se trata do "ponto central comum às diversas correntes que reinvidicam a regulação" (BOYER, 1990, p. 46 - grifos do autor).

Considerando a concepção acima explicitada, Boyer afirma que os estudos em termos de regulação foram progressivamente se desenvolvendo, esbarrando em três paradoxos: 1. Por que e como, numa formação econômica dada, passamos de um crescimento forte e regular para uma quase estagnação e uma instabilidade das sequências conjunturais? 2. Durante um mesmo momento histórico, como explicar que crescimento e crise assumem formas nacionais significativamente diferentes, com o aprofundamento dos desequilíbrios em certos países e a afirmação de uma relativa prosperidade em outros? 3. Finalmente, por que, apesar de certas invariantes gerais, as crises apresentam aspectos diferenciados ao longo do tempo, por exemplo, no século XIX, no entre-guerras e nos dias de hoje? "Na realidade, esses três paradoxos inserem-se numa mesma questão geral: a da variabilidade no tempo e no espaço das dinâmicas econômicas e sociais" (BOYER, 1990, p. 61).

Nesse sentido, o autor coloca a noção de regime de acumulação como uma noção importante para entender a regulação e faz o seguinte questionamento: como um pocesso tão contraditório pode ser bem-sucedido em longo prazo? Elementos caracterizam esse processo contraditório: circulação de mercadorias, crises, modos de produção não-capitalistas, lucro, dentre outros. Nesse entendimento, estudar as possibilidades de acumulação em longo prazo significa tentar encontrar as diferentes regularidades sociais e econômicas referentes a diferentes elementos da cadeia produtiva. A partir daí pode-se definir um regime de acumulação.

Entenderemos por esse termo o conjunto das regularidades que asseguram uma progressão geral e relativamente coerente da acumulação do capital, ou seja, que permite absorver ou repartir no tempo as distorções e desequilíbrios que surgem permanentemente ao longo do próprio processo (BOYER, 1990, pp. 71 e 72).

Esse autor ressalta que o regime de acumulação pode assumir formas variadas, o que traz consequências em termos de dinâmicas econômicas e de configuração social 
que não podem ser comparáveis. Para situar a teoria da regulação, ele também destaca a relevância de entendermos as formas institucionais ${ }^{4}$ historicamente determinadas, como por exemplo, a relação salarial, a concorrência e a inserção internacional, que intervem na determinação do regime de acumulação. Ao buscar uma definição do que seja um modo de regulação ele considera os elementos acima destacados e afirma:

Consequemente, qualificaremos como modo de regulação todo um conjunto dos procedimentos e de comportamentos, individuais ou coletivos, com a tripla propriede de: reproduzir as relações sociais fundamentais através da conjunção de formas institucionais historicamente determinadas; sustentar e pilotar o regime de acumulação em vigor; garantir a compatibilidade de um conjunto de decisões descentralizadas, sem que seja necessária a interiorização dos princípios de ajustamento do sistema como um todo por parte dos atores econômicos (BOYER, 1990, p. 80 - grifos do autor).

Ele nos diz que essa noção visa substituir a teoria da decisão individual e o conceito de equilíbrio geral como ponto de partida para estudo das questões econômicas, mas também reconhece a existência de certa autonomia das estratégias individuais e a heterogeneidade dos comportamentos no interior de um mesmo conjunto de formas institucionais.

Em meio a essa emergência conceitual e teórica, o conceito de regulação estatal vem ganhando destaque na atualidade, já que os debates têm relacionado o tema às novas configurações que o Estado vem assumindo por meio da implementação de políticas públicas com maior foco no controle da vida social e econômica (AZEVEDO; GOMES, 2009).

A regulação estatal assume uma forma de intervenção que pode ser visível, quando efetuada por leis, normas e regras ou/e simbólica, quando a criação de regras busca atingir objetivos não explícitos. Isso acontece em determinados campos como saúde, educação e economia. Pode-se dizer que a regulação também se expressa por intermédio de práticas específicas de certas profissões e pela regulação das profissões, uma vez que a relação do trabalhador com seu trabalho produz o trabalho e o próprio trabalhador (AZEVEDO; GOMES, 2009). Dessa forma, ao regular o trabalho, regula-se também o trabalhador.

\footnotetext{
${ }^{4}$ As formas institucionais primordiais do capitalismo são a moeda, a relação salarial e a concorrência que operam essencialmente no espaço do Estado-Nação. A essas formas ainda são acrescentas mais duas: tipos de inserção no sistema internacional e formas do Estado. Elas são entendidas como os parâmetros que moldam as estruturas e o corpo da regulação, assumindo um papel de mediadoras, forjando, assim, o modo de regulação. (BOYER, 2004).
} 
Segundo os autores acima citados, a atuação do Estado no controle de políticas públicas pode ser exercida de duas formas: o Estado pode elaborar estratégias em que se regula por meio dos resultados, responsabilizando os envolvidos, ou pode regular e intervir através de ações por dentro do processo assumindo a responsabilidade. E nos alertam que o período histórico em que se aprofunda o sentido característico e específico do termo regulação na intervenção estatal coincide com a diminuição da própria intervenção estatal, passando a ser disseminado um novo referencial teórico e normativo das políticas públicas apoiado em pressupostos neoliberais. Ou seja, a regulação vai ganhando novas formas no interior da ação estatal. (AZEVEDO; GOMES, 2009).

Nesse contexto, afirmam que o conceito de regulação foi incorporado por discursos e práticas governamentais para análises de ações voltadas a diferentes campos sociais, e entre eles está a educação. Isso não significa que as práticas e os discursos governamentais sejam monolíticos e homogêneos. Muito pelo contrário,

[...] a regulação se torna bandeira de "todos", porque passou a ser fundamento político para a re-funcionalização do modo de produção capitalista a partir dos anos de 1970, fortalecendo-se e consolidando-se como política de gestão social que vincula gestão macroeconômica à micropolítica do cotidiano (AZEVEDO; GOMES, 2009, p. 96-97).

De todo modo, é importante destacar que o conceito de regulação estatal está baseado em princípios teórico-metodológicos que se diferenciam de intervenção. No período entre guerras, por exemplo, o crescimento econômico foi potencializado por políticas sociais de intervenção do Estado. Com a crise de superprodução e subconsumo, há o embate da doutrina liberal não intervencionista e da doutrina intervencionista. 0 preconceito liberal contra o intervencionismo do Estado, defende a liberdade de mercado, argumentando que o Estado não deve interferir na economia, pois ela se autorregula. Nesse embate, a doutrina neoliberal se fortaleceu em diversos países, de forma que os elementos da intervenção passaram a ter um sentido negativo no que diz respeito à atuação do Estado nas políticas públicas. Isso porque num sentido mais geral, essa palavra se associa à intromissão e à ingerência.

Sendo assim, certamente as ações que o Estado passou a desempenhar na economia foram designadas como "intervencionistas", sobretudo por estarem, mais uma vez, se confrontando com os postulados do liberalismo clássico em relação a elas. Estes pregavam a vigência do Estado Guardião, responsável tão somente pelas práticas que, no plano econômico, garantissem a liberdade de mercado e o funcionamento das 
leis naturais de auto-regulação. Deste modo, a noção que passa a ser utilizada, para categorizar as novas formas e funções do Estado, traz subjacente o postulado de negação dessas atribuições, própria do período áureo do liberalismo, que vinha tendo vigência, como orientador das ações, até então (AZEVEDO \& GOMES, 2009, p. 99).

A utilização da teoria da regulação, para a análise de políticas públicas, vem da necessidade de entender o Estado através de sua ação por meio de processos que garantem o controle da intervenção pública (BARROSO, 2005). Isso também vale para os estudos sobre a ação do Estado nas políticas de educação.

O sistema de educação ou a educação escolar é uma componente central do modo de regulação em qualquer sociedade diferenciada e desigual. A montagem e a existência de instituições educacionais diferentes, as práticas de avaliação da aprendizagem e de avaliação das instituições de ensino da educação básica e superior, as formas de regulação intrasistêmica que definem formas de comportamentos, títulos e status não apenas são condicionadas pela estrutura social historicamente engendrada, como se relacionam com o mundo do trabalho, o qual tem como fundamento um sistema de recompensas pecuniária e simbólica. Assim, pode-se compreender por que a educação é parte importante do modo de regulação e dele não pode se desvencilhar. Talvez seja a educação, como processo social e escolar, o locus principal do modo de regulação, porque é ela mesma constituinte das formas e processos da reprodução social (AZEVEDO \& GOMES, 2009, p. 102).

Nesse sentido, passaremos a discorrer um pouco sobre a relação entre regulação e intervenção do Estado na educação, já que entendemos que a noção de regulação tem sido utilizada com um amplo repertório para a análise das políticas públicas de educação, contribuindo, assim, para evidenciar e tornar compreensíveis as questões relativas ao contexto educacional.

\section{A regulação do Estado na educação}

Nas políticas educativas internacionais, o termo "regulação", segundo um breve sumário realizado por Barroso (2005), ocorre em dois contextos: no primeiro, em países francófonos, o termo aparece associado ao debate sobre a reforma educacional para sua modernização, criticando a intervenção do Estado e reforçando uma imagem menos prescritiva e mais regulamentadora, orientada por controle de resultados. 0 Estado continua a investir parte do seu orçamento em educação, mas se retira das ações educacionais cotidianas, de organização e gestão, transferindo-as para a iniciativa privada, em parcerias e concorrências, assumindo a função de avaliador controlando pelos resultados. 
No segundo contexto, em países anglo-saxônicos onde acontecem políticas de cunho mais conservador e neoliberal, o termo aparece associado ao conceito de desregulamentação, alterando o modelo tradicional de intervenção do Estado, de coordenação e direção do sistema público de educação. Não se trata de simples alteração do termo, mas, parcialmente, da mudança da regulação pelo Estado para a regulação de iniciativa privada, criando o "quase mercado5", ou ainda cabe afirmar que a regulação é observada como privatização da educação.

Esse movimento está vinculado à consolidação das políticas de cunhos neoliberal que pregou a redução do papel do Estado nas políticas sociais, criando o mercado ou quase mercado nos setores tradicionalmente públicos como saúde, educação, transportes, entre outros (BARROSO, 2005).

Na luta pela hegemonia política, ocorrido nas últimas décadas do século XX no Brasil, a corrente neoliberal ganha espaço naquele momento político, instaurando o modelo neoliberal de governar favoreceu o avanço de ações de regulação nas políticas educacionais, como é o caso da disseminação das avaliações externas. Nesse processo, também aumentaram a atuação dos organismos internacionais como Banco Mundial (BM), o Fundo Monetário Internacional (FMI), o Banco Interamericano de Desenvolvimento (BID) e a Organização das Nações Unidas para a Educação, a Ciência e a Cultura (UNESCO), estabelecendo ações que vinculam a qualidade da educação com o desenvolvimento econômico.

Tal movimento avançou no Brasil como consequência das mudanças que ocorreram nas décadas de 1980 e 1990. "É um modelo de desenvolvimento que informa a emergência do mercado regulador da economia e postula a redução do papel do Estado no campo social" (NARDI, 2010, p. 206).

Corroborando o pensamento de Nardi, Palma aponta que "o tipo de globalização que se opera nesse contexto neoliberal irá transformar radicalmente a ação do Estado no campo das políticas sociais" (PALMA FILHO, 2007, p. 10). Ou seja, a regulação, no sentido acima colocado, vincula-se a uma perspectiva neoliberal. A força da perspectiva neoliberal se expressa em uma variedade de políticas em diferentes lugares, cujos discursos buscam criar uma "noção de que as reformas são uma necessidade natural, constituem-se em parte inevitável da globalização do mercado internacional e de uma

\footnotetext{
${ }^{5} \mathrm{O}$ quase-mercado na educação consiste na gestão da educação pública por meio de princípios e
} valores do mercado, tais princípios não contemplam a utopia da transformação (BARROSO, 2005). 
economia cada vez mais baseada no conhecimento que, portanto, exige mudanças radicais na forma de organizar, conceber e desenvolver a educação. Isso conduz a um deslocamento da esfera do político para a esfera do econômico, que passa a ser determinante para as definições educativas (HIPÓLITO, 2010, p. 1340).

Assim sendo, no contexto da educação, o neoliberalismo se expressa por meio de várias reformas estruturais, destinadas a reduzir a intervenção do Estado na administração do serviço educativo por meio de discursos que criticam a qualidade do serviço público estatal, abrindo espaço para a intervenção do mercado, subordinando as políticas de educação à lógica econômica global, importando para essas políticas valores como competição, concorrência, empreendedorismo e excelência, promovendo medidas de privatização. Observamos, com isso, a transformação da ideia do serviço público em um serviço para clientes. Nesse sentido, a educação, enquanto um bem para todos, torna-se algo diverso, desigualmente acessado. Na aparência, um mercado único, enquanto na essência funciona como diferentes submercados que ofertam produtos diferenciados com natureza e qualidade desiguais.

Nas investigações realizadas por Barroso (2005), analisando diversos modos de regulação da educação, foram identificados três níveis: o nacional, que tem como eixo a regulação institucional; o intermediário, voltado a instâncias de regulação com ações em territórios intermediários do sistema educativo, na interface entre o nacional e o local; e o nível local, que se refere aos modos de regulação internos de cada escola. Nesse sentido, ele nos adverte:

[...] falta ao mercado (entre outras coisas), a sensibilidade social que permita atender aos que pelas mais diversas razões, exigem mais tempo, mais dinheiro e melhores recursos para obterem o sucesso educativo a que têm direito. Por outro, o Estado social não pode estar limitado (como querem os defensores de políticas neoliberais neste domínio) a cumprir funções do "carro-vassoura" dos excluídos que o mercado enjeita (por questões de rentabilidade e eficácia). [...] E, aqui o recurso à metáforado "carro-vassoura" justifica-se plenamente se nos recordamos que esta designação é dada, nas corridas de ciclismo, ao carro que vai na cauda do pelotão para recolher os ciclistas que são obrigados a desistir, por não conseguirem acompanhar o andamento dos outros corredores (BARROSO, 2005, p. 746).

Como se pode observar, no movimento inerente à sociedade, há perspectiva ampla do termo regulação e sua vinculação com a ação estatal na educação. Concordamos com Freitas (2005, p. 913) ao afirmar que o sentido do termo regular "é 
vocação de toda política pública, entretanto 'regulação' foi um termo construído no interior das 'políticas públicas neoliberais", ou seja, o Estado se abre para a iniciativa privada e descentraliza suas ações, mas continua firme no propósito de regular as políticas de interesse público. Mas, não se trata de qualquer regulação, conforme afirma Hipólito (2010, p. 1339), trata-se de uma regulação neoliberal que se expressa no âmbito educativo através de "ações notadamente gerencialistas [...] apresentadas como solução para todos os problemas da educação pública, articuladas, como se sabe, a partir de pressupostos da eficiência, dos resultados, da avaliação e da competência".

Os novos modos de regulação possuem base de sustentação em diferentes dispositivos, como o desenvolvimento das avaliações e a regulação por resultados (NOGUEIRA, 2015). Tais dispositivos institucionais caracterizam os modos de regulação praticados pelas políticas públicas para educação em andamento na atualidade.

A introdução de sistemas de avaliação da educação e do desempenho docente é crucial para essa regulação por parte do Estado, que passa a controlar e a avaliar desde longe, por meio da contratação de terceiros para realizar a avaliação externa - considerada como prestação de contas à sociedade civil (accountability). Tais modelos gerenciais são baseados na qualidade e no mérito e os problemas da educação ficam reduzidos a problemas técnico-gerenciais (HIPÓLITO, 2010, p. 1339).

Baseadas no debate acima, buscaremos a seguir, desvelar os sentidos de que a avaliação externa e em larga escala vem se revestindo na política de educação brasileira. Isso por concordamos com Nogueira (2015) que afirma ser esse tipo de avaliação um dos dispositivos de regulação da educação nacional.

\section{A avaliação externa e em larga escala como mecanismos de regulação}

A avaliação externa, como elemento de regulação, está atualmente, em alta nas políticas educacionais nacionais e internacionais, sendo elemento presente no sistema educacional de diferentes países. Esse movimento está atrelado à ideia de que a avalição é um dos motores de transformação das políticas públicas educacionais, mesmo quando consideramos seu caráter complexo e contraditório, no que diz respeito às concepções e práticas. Dias Sobrinho (2004) há tempos nos alerta que a avaliação tem instrumentalizado as reformas educacionais, vindo a produzir mudanças nas configurações e nas prioridades dos sistemas educativos e que, enquanto componente da política educacional, vem sendo considerado uma exigência social, já que envolve responsabilização, justiça e desigualdade social. 
No Brasil, nas últimas décadas do século XX a avaliação externa e em larga escala tem sido bastante estudada, isso porque ela vem sendo bastante utilizada para acompanhar o desempenho das redes de ensino, redefinindo e reorientando políticas públicas na educação. É certo que os resultados desse tipo de avaliação podem fornecer importantes informações acerca da escola e seu funcionamento, das condições escolares, da aprendizagem dos alunos, do desempenho dos professores e servir como recurso de monitoramento da qualidade da educação. Como nos aletaram Tavares e Neubert (2014, p. 43), "a recuperação da qualidade da educação na primeira década deste século, decorrente do avanço do desempenho médio das redes públicas, esteve associada à adoção de políticas educacionais e reformas que sempre tiveram nas avaliações em larga escala um elemento central". De todo modo, é certo destacar que é fundamental observar qual o conceito de qualidade está sendo tomado como parâmetro.

Diretamente ligados ao desempenho dos estudantes e das escolas, a avaliação externa e em larga escala pode ser considerada um mecanismo bastante importante neste momento no Brasil. Isso por conta da relevância que o Sistema de Avaliação da Educação Básica (SAEB) e o Índice de Desenvolvimento da Educação Básica (IDEB) vêm ganhando nos últimos anos quando analisamos sua influência na definição de políticas para educação. Como se sabe, o IDEB tem se constituído como parâmetro para aferir a qualidade da rede pública de ensino por meio de testes padronizados cujos resultados são apresentados na forma de dados quantitativos.

Concordando com Marques (2017, p. 2), é possível afirmar que o debate sobre a educação de qualidade na atualidade é um ponto central, no entanto os sentidos conferidos ao termo "qualidade" são diferenciados. "Dessa forma, pode-se falar em qualidades da educação, a depender da perspectiva teórica e do projeto social em que se inserem os que dela estão falando". Ao se implementar uma política de avaliação dos sistemas educativos tem-se por base uma concepção de qualidade, e é correto dizer que cabe aos pesquisadores perscrutar os sentidos dados a essa concepção.

Para explicitar melhor esse processo, destacamos que a política de avaliação educacional ${ }^{6}$ no Brasil com o uso de avaliação em larga escala teve início nos anos 1990

\footnotetext{
${ }^{6} \mathrm{O}$ sistema de avaliação educacional no Brasil hoje conta com diferentes instrumentos para avaliar as diferentes etapas da educação básica. Podemos destacar o Exame Nacional do Ensino Médio (ENEM) que surgiu em 1998; o SAEB, que sofreu alterações ao longo dos anos e atualmente é composto pela Avaliação da Educação Básica (ANEB), Avaliação do Rendimento Escolar (ANRESC/Prova Brasil) e Avaliação Nacional da Alfabetização (ANA); a Provinha Brasil, destinada a avaliar o desempenho de estudantes do segundo ano do ensino fundamental. www.inep.gov.br.
} 
e surge para obter dados mais detalhados sobre a realidade da educação. Esse período coincide com o processo de redemocratização do país, momento em que a busca pela universalização e pela qualidade da educação propiciou contexto para a construção de instrumentos de avaliação em larga escala. (ROCHA, 2014).

De acordo com Freitas (2007, p. 157), os estados brasileiros fizeram uso, através de iniciativas estaduais, em interação com o MEC/INEP, em especial com o SAEB, para a consolidação de seus sistemas estaduais de avaliação, subordinando tais avaliações e resultados ao repasse de verbas. As razões alegadas, oficialmente, giram em torno de imperativos de ordem constitucional, político-administrativa, metodológica-técnica e cultural.

0 que se percebe nesse mecanismo de regulação é uma vinculação direta com a melhoria da qualidade da educação, no entanto a perspectiva de qualidade anunciada pelo discurso da avaliação de sistemas via testes estandardizados buscam enfatizar a eficácia e eficiência dos resultados acadêmicos dos estudantes e corroboram com exigências do mercado e defendem a capacidade competitiva da sociedade em geral.

As avaliações externas constituem uma mudança importante trazida para as políticas educacionais como elemento regulador (AFONSO, 2005). 0 autor aponta que, por meio delas, direciona-se a ênfase nos resultados e nos produtos, desvalorizando o processo. 0 caminho traçado geralmente está vinculado a uma mudança no próprio sistema de responsabilização, ou seja, passando de sistemas que responsabilizam as pessoas por processos, para sistemas que responsabilizam pessoas por resultados. Parte-se da premissa de que sem a presença de resultados que possam ser medidos não se consegue estabelecer uma base de responsabilização em que se possa acreditar, daí a necessidade de avaliação do desempenho e da criação de indicadores de desempenho, no entanto educação é processo de subjetivação e não mercadoria e produto.

Os valores de domínio público como igualdade, solidariedade, justiça e cidadania, estão ameaçados diante dos valores do mercado e outras lógicas do setor privado, viabilizadas por uma política presente em certas modalidades de avaliação, como estratégia de controle de despesas públicas e mudança de cultura do setor público, centrada na eficiência e na produtividade, sob controle direto do Estado (AFONSO, 2005). 
Sousa e Oliveira (2003, p. 875), nessa mesma linha de raciocínio, consideram que a avaliação encerra como uma de suas potencialidades funcionais a de ser "peça central nos mecanismos de controle, que se deslocam dos processos para os produtos, transferindo-se o mecanismo de controle das estruturas intermediárias para a ponta".

Com essa característica, a avaliação em larga escala tanto se constitui um exercício de poder, quanto pode acionar mecanismos de regulação capazes de adentrar o contexto escolar de uma forma sutil, como se compusesse a dinâmica interna da escola, influenciando processos, mas com foco nos resultados. Nessa linha de raciocínio, a avaliação é um dispositivo concreto de regulação educacional, uma vez que os usos dos seus resultados vêm sendo incorporados aos sistemas de ensino, seja com o discurso no sentido de garantir direitos, seja para acionar mecanismos de responsabilização (NOGUEIRA, 2015, p. 31).

Direcionadas à ideologia do mercado, as avaliações externas com resultados publicizados vão sendo justificadas por um discurso que defende a necessidade de medir, através de índices, a qualidade educacional, ao mesmo tempo em que passam a reorientar as políticas em busca dessa qualidade, acarretando controle sobre as escolas e docentes para que desenvolvam práticas que gerem produtos onde se observem a eficácia do sistema educacional.

0 modelo de governo de raiz neoliberal se consolida trazendo a lógica do mercado para o serviço público, aumentando o controle do Estado sobre a educação e estimulando a concorrência por meio de práticas competitivas em instituições escolares. Forlatecendo, assim, esse modelo de regulação de políticas públicas com base no controle de resultados e na descentralização.

Assim, vamos identificando diferentes impactos que são gerados por esses mecanismos de regulação. Alguns dos exemplos desses impactos são os que ocorrem sobre o trabalho do professor que, muitas vezes, fica delimitado por apostilas e exames padronizados produzidos, inclusive, por corporações. No desenvolvimento de sua ação, o professor vê colocada em questão sua autonomia pedagógica e passa a ser um reprodutor das cartilhas, um burocrata visando metas, ou seja, trabalhando numa lógica empresarial e esvaziando o seu papel educativo, o que resulta em sérios comprometimentos na formação dos estudantes e na autonomia pedagógica do professor.

\section{Considerações Finais}


A regulação exercida pelo Estado está ligada a dimensões políticas, sociais e economicas, consistindo num certo tipo de fundamento para refuncionalização do modo de (re)produção capitalista. Assim, é possível dizer que o objeto de regulação é temporário e inconstante, visto que depende do movimento do real na correlação de forças que demarcam as formas de socialibilidade no contexto do modo de produção acima aludido.

Os modos de regulação da educação vêm sendo condicionados por um movimento homogeneizante em nível internacional, o que desconsidera as características e necessidades locais. Assim, a avaliação em larga escala tem sido utilizada enquanto dispositivo de regulação educacional, cuja preocupação tem se voltado a impor um currículo nacional controlado através de resultados. A partir de um discurso neoliberal e neoconservador, utiliza como uma das justificativas a ineficácia dos métodos pedagógicos e o mau uso da autonomia profissional dos professores, fortalecendo o papel do Estado no controle social e na racionalização dos investimentos públicos através de políticas de prestação de contas sem práticas democráticas correspondentes.

Observamos que os resultados produzidos pelas avaliações estão articulados à medidas de privatização e terceirização transformando-se em elementos de pressão no interior das escolas, pois coloca o trabalho docente sob suspeita, responsabilizando docentes e gestores escolares pelos resultados quantitativos dos estudantes, desconsiderando os processos e as condições objetivas que permeiam as práticas docentes.

\section{Referências}

AFONSO, A. J. Avaliação educacional: regulação e emancipação: para uma sociologia das políticas avaliativas contemporâneas. 4. ed. São Paulo: Cortez, 2005.

AFONSO, A. J. A Redefinição do Papel do Estado e as Políticas educativas: elementos para pensar a transição. Sociologia, Problemas e Práticas, n. 37, 2001, pp. 33-48. Disponível em <http://sociologiapp.iscte-iul.pt/pdfs/3/24.pdf> Acesso em: 2 junho, 2017

AZEVEDO, J. M. L. de; GOMES, A. M. Intervenção e regulação: contribuição ao debate no campo da educação. Linhas Críticas, Brasília, v. 15, n. 28 p. 95-107, jan./jun. 2009.

BARROSO, J. O Estado, a educação e a regulação das políticas públicas. Educação e Sociedade, Campinas, v. 26, n. 92, p. 725-751, Especial- Out. 2005. Disponível em: <http://www.scielo.br/pdf/es/v26n92/v26n92a02.pdf>. Acesso em: 12 maio, 2016.

BOYER, Robert. A teoria da regulação: os fundamentos. Tradução Paulo Cohen. - São Paulo: Estação Liberdade, 2004. 
BOYER, Robert. A teoria da regulação: uma análise crítica. Tradução de Renée Barata Zicman. São Paulo: Nobel, 1990.

DIAS SOBRINHO, José. Avaliação ética e política em função da educação como direito público ou como mercadoria? Educação e Sociedade. Campinas, vol. 25, n. 88, p. 703725, Especial - Out. 2004.

FREITAS, N. T. de. A avaliação da educação básica no Brasil: dimensão normativa pedagógica e educativa. Campinas, SP: Autores Associados, 2007. (Coleção Contemporânea).

FREITAS, L. C. de. Os reformadores empresariais da educação: da desmoralização do magistério à destruição do sistema público de educação. Educação e Sociedade, Campinas, v. 33, n. 119, p. 379-404, abr.-jun. 2012b. Disponível em http://www.scielo.br/pdf/es/v33n119/a04v33n119.pdf

HYPOLITO, Álvaro Moreira. Políticas Curriculares, Estado e Regulação. Educação \& Sociedade, vol. 31, núm. 113, octubre-diciembre, 2010, pp. 1337-1354.

MARQUES, L. R. Qualidade educacional: sentidos hegemônicos em escolas com bom desempenho em avaliações de larga escala. Jornal de Políticas Educacionais. V. 11, n. 23. Dezembro de 2017.

NOGUEIRA, Rivanda dos Santos. Avaliação em larga escala como regulação: o caso do Sistema Estadual de Avaliação da Aprendizagem Escolar - SEAPE/ACRE. Curitiba, 2015. 260 f. Orientadora: Prof ${ }^{a}{ }^{-}$Dr $^{-}$Andréa Barbosa Gouveia Tese (Doutorado em Educação) - Setor de Educação, Universidade Federal do Paraná. Curitiba, 11/12/2015.

PALMA FILHO, J. C. Impactos da globalização em políticaspúblicas em educação. In: PALMA FILHO, J. C.; TOSI, P. G. (Orgs.). Política educacional. São Paulo: Páginas e Letras Editora e Gráfica, 2007.

ROCHA, Gladys.; MARTINS, Raquel Fontes. A Apropriação de Habilidades de Leitura e Escrita na Alfabetização: estudo exploratório de dados de uma avaliação externa. Rio de Janeiro: Ensaio: aval.pol.públ.Educ.; 22(85); 977-1000; 2014-12. Disponível: www.scielo.br.

SOUSA, S. M. Z. L.; OLIVEIRA, R. P. Políticas de avaliação da educação e quase mercado no Brasil. Educação e Sociedade, Campinas, v. 24, n.84, p. 873-895, 2003. Acesso em: 18 jul. 2014.

TAVARES J, F. T.; NEUBERT, L. F. A qualidade da educação e a disseminação de sistemas de avaliação. Estudos em Avaliação Educacional, São Paulo, v. 25, n. 59, p. 22-48, set./dez. 2014. 

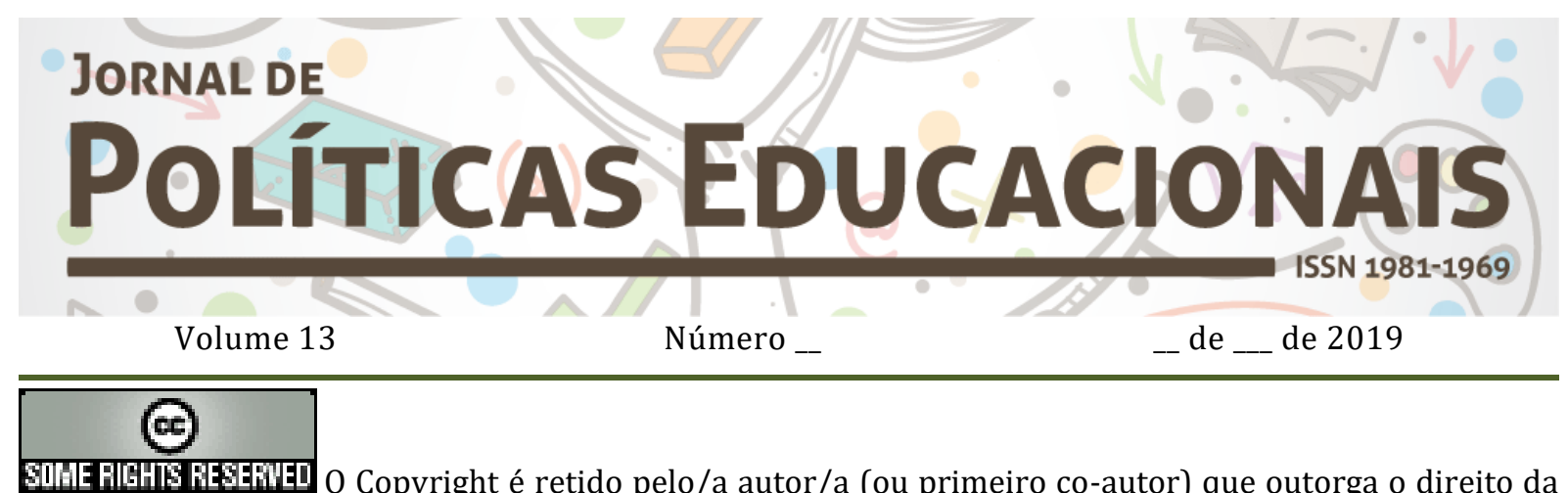

0 Copyright é retido pelo/a autor/a (ou primeiro co-autor) que outorga o direito da primeira publicação ao Jornal de Políticas Educacionais. Mais informação da licença de CreativeCommons encontram-se em http://creativecommons.org/licenses/by-nc-nd/2.5. Qualquer outro uso deve ser aprovado em conjunto pelo/s autor/es e pelo periódico.

Jornal de Políticas Educacionais é uma publicação do Núcleo de PolíticasEducacionaisdo Setor de Educação da Universidade Federal do Paraná - NuPE/UFPR, em consórcio com a Linha de Pesquisa em Políticas Educacionais do Programa de Pós-Graduação em Educação - PPGE/UFPR, que aceita colaboração, reservando-se o direito de publicar ou não o material espontaneamente enviado à redação. As colaborações devem ser enviadas ao NuPE/UFPR, conforme orientações contidas nas páginas do periódico na internet: http://revistas.ufpr.br/ipe.

\author{
Indexação: \\ BBE - Biblioteca Brasileira de Educação (MEC/INEP) \\ Clase (Base de Datos Bibliográfica de Revistas de Ciencias Sociales y Humanidades) \\ Diadorim - Diretório de Política de Acesso Aberto das Revistas Científicas Brasileiras (IBICT) \\ Google Scholar \\ Index Copernicus \\ Portal de Periódicos (CAPES) \\ SER - Sistema Eletrônico de Revistas da Universidade Federal do Paraná (SER/UFPR) \\ Sumários de Revistas Brasileiras (FUNPEC-RP) \\ DRJI - Directory of Research Journals Indexing
}

(Periódico integralmente disponível apenas em via eletrônica)

Jornal de Políticas Educacionais / Núcleo de Políticas Educacionais da Universidade Federal do Paraná -

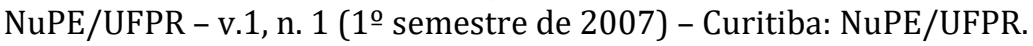

Volume 13, número _- Mês de 2019

ISSN 1981-1969

1. Educação - Periódicos. 2. Política Educacional - Periódicos. I. NuPE/UFPR

Comitê Editorial:

Elisângela Scaff (UFPR)

Ana Lorena Bruel (UFPR)

Gabriela Schneider (UFPR)

Conselho Editorial:

Andréa Barbosa Gouveia (UFPR), Ângela Hidalgo (UNICENTRO), Cesar GernominoTello (Universidad Nacional TresFebrero, Argentina),Gladys Beatriz Barreyro (USP), Juca Gil (UFRGS), Jefferson Mainardes 
LINDOSO, R. C. B.; SANTOS, A. L. F. Política educacional e a avaliação em larga escala como elemento de regulação da educação

(UEPG), João Ferreira de Oliveira (UFG), Luiz Souza Júnior (UFPB), Marcos Edgard Bassi (UFSC), Regina Maria Michelotto (UFPR), Robert Verhine (UFBA), Rosana Cruz (UFPI), Rubens Barbosa Camargo (USP), Sebastián Donoso Díaz (Universidad de Talca, Chile), Taís Moura Tavares (UFPR), TheresaAdrião (UNICAMP), Vera Peroni (UFRGS).

Jornal de Políticas Educacionais

Universidade Federal do Paraná

Setor de Educação

Núcleo de Políticas Educacionais - NuPE/UFPR

Rua Gal. Carneiro, 460 - 4o andar - Sala 407/C

80.060-150 - Curitiba - PR - Brasil

Tel.: 41-3360-5380

jpe@ufpr.br

http://revistas.ufpr.br/jpe 